\title{
Molecular Docking Study of Several Seconder Metabolites from Medicinal Plants as Potential Inhibitors of COVID-19 Main Protease
}

\author{
(1) Sinan BiLGINER ${ }^{1 *}$, (1) Sefa GÖZCÜ2 ${ }^{2}$ (1) Zuhal GÜVENALP3 \\ 1Atatürk University, Faculty of Pharmacy, Department of Pharmaceutical Chemistry, Erzurum, Türkiye \\ 2Erzincan Binali Yıldırım University, Faculty of Pharmacy, Department of Pharmacognosy, Erzincan, Türkiye \\ ${ }^{3}$ Atatürk University, Faculty of Pharmacy, Department of Pharmacognosy, Erzurum, Türkiye
}

\begin{abstract}
Objectives: Coronaviruses (CoVs) cause infections that affect the respiratory tract, liver, central nervous, and the digestive systems in humans and animals. This study focused on the main protease (Mro) in CoVs (PDB ID: 6LU7) that is used as a potential drug target to combat 2019-CoV. In this study, a total of 35 secondary metabolites from medical plants was selected and docked into the active site of 6LU7 by molecular docking studies to find a potential inhibitory compound that may be used to inhibit Coronavirus Disease-2019 (COVID-19) infection pathway.

Materials and Methods: The chemical structures of the ligands were obtained from the Drug Bank (https://www.drugbank.ca/). AutoDockTools (ADT ver. 1.5.6) was used for molecular docking studies. The docking results were evaluated using BIOVIA Discovery Studio Visualizer and PyMOL (ver. 2.3.3, Schrodinger, LLC).

Results: Pycnamine, tetrahydrocannabinol, oleuropein, quercetin, primulic acid, kaempferol, dicannabidiol, lobelin, colchicine, piperidine, medicagenic acid, and narcotine is found to be potential inhibitors of the COVID-19 Mpro. Among these compounds, pycnamine, which was evaluated against COVID-19 for the first time, showed a high affinity to the COVID-19 $\mathrm{M}^{\text {pro }}$ compared with other seconder metabolites and reference drugs.

Conclusion: Our results obtained from docking studies suggest that pycnamine should be examined in vitro to combat 2019-CoV. Moreover, pycnamine might be a promising lead compound for anti-CoV drugs.
\end{abstract}

Key words: COVID-19, molecular docking, pycnamine, seconder metabolites

\section{INTRODUCTION}

Coronaviruses (CoVs) cause disorders in both the respiratory tract and the digestive system in humans and animals.' During an epidemic in Wuhan, China at the end of 2019, the new CoV strain was identified and named 2019-nCoV. In a very short time, this newly emerging virus spread to almost all countries and the disease is officially named as Coronavirus Disease-2019 (COVID-19) by World Health Organization (WHO). ${ }^{2}$ According to WHO's COVID-19 Weekly Epidemiological Update Report released on May 11, 2021, the number of confirmed cases reached 157,362,408 including 3,277,834 deaths in the world as of May $9,2021^{3}$
Currently, there are several vaccines for COVID-19, but no antiviral drugs are available for specific treatment of COVID-19. However, some antiviral drugs such as lopinavir, ritonavir, remdesivir, and nelfinavir have been using to prevent further complications and organ damage caused by COVID-19.4 Among all these drugs, nelfinavir, which has been used in clinics, was found as the most potential inhibitor drug against COVID-19 main protease $\left(\mathrm{M}^{\text {pro }}\right)$ based on its docking score according to the docking studies conducted by Xu et al. ${ }^{5}$ In docking studies, $\mathrm{M}^{\mathrm{pro}}$ is used as a potential drug target to combat 2019-CoV. ${ }^{6-8}$

Secondary metabolites obtained from medicinal plants and their semi-synthetic derivatives have been widely used in new 
drug development. Therefore, the use of secondary metabolites purified from medicinal plants in drug development against severe acute respiratory syndrome (SARS)-CoV becomes important.9 There are many studies reporting the antiviral effects of many compounds with alkaloid, ${ }^{10-12}$ flavonoid, ${ }^{13,14}$ monoterpene, ${ }^{15-19}$ sesquiterpene lactone, ${ }^{20,21}$ saponoside, ${ }^{22,23}$ and aryl alkene ${ }^{24,25}$ structures.

In this study, the potential innhibitory effects of alkaloids (atropine, caffeine, castanospermine, codeine, ephedroxane, hygrine, cuscohygrine, colchicine, lobeline, tussilagine, punicalagin, papaverine, pycnamine, piperidine, scopolamine, morphine, narcotine, pelletierine, ricinine), cannabinoids (cannabidiol and tetrahydrocannabinol), monoterpenes (citral A, thymol, oleuropein, and harpagoside), sesquiterpene lactone, e.g. artemisinin, saponins (primulic acid and medicagenic acid), aryl alkene (aromatic ketone), e.g. gingerol, and flavonoids (quercetin and kaempferol) were investigated on 2019-CoV Pro via molecular docking studies. We hope that the findings of this study will contribute to drug research to combat COVID-19 and direct the researchers working in this field to further designs.

\section{MATERIALS AND METHODS}

\section{Experimental in silico part}

The 2019-CoV Mpro (PDB ID: 6LU7) structure was obtained from The Protein Data Bank (PDB, https://www.rcsb.org/). The $\mathrm{pdb}$ file of the $6 \mathrm{LU} 7$ protein was prepared using chain $A$ and transferred to AutoDockTools (ADT ver. 1.5.6). Water molecules of the structures were removed and only polar hydrogen and Kollman charges were added to the proteins. Finally, the pdbqt files of the proteins were saved. ${ }^{26}$

Chemical structures of the ligands were obtained from the Drug Bank (https://www.drugbank.ca/). The ligands unavailable in the Drug Bank were drawn in ChemDraw (Professional, version 19.0.1.28), passed to ChemDraw 3D (professional, version 19.0.1.28) and minimized. Torsion of the ligands was examined and then the files of the ligands were saved as pdbqt format by AutodockTools (ADT ver. 1.5.6).

The active site of the 6LU7 was defined using BIOVIA Discovery Studio Visualizer (v20.1.0.19295). AutoDockTools (ADT ver. 1.5.6) was used for molecular docking studies. Lamarckian genetic algorithm with local search was used as a search engine, with 10 runs. The active site of the protein was defined by a grid box of $60 \times 60 \times 60$ points. Ten conformers of the ligands were considered to evaluate the docking results. Finally, the conformer with the lowest binding free energy was evaluated by BIOVIA Discovery Studio Visualizer and PyMOL (ver. 2.3.3, Schrodinger, LLC). ${ }^{26}$

\section{Statistical analysis}

No statistical analysis was used in this study.

\section{RESULTS}

CoVs cause infections that affect the respiratory tract, liver, central nervous and the digestive systems in humans and animals. ${ }^{27}$ This study focused on the Mpro in CoVs (PDB ID: 6LU7) that is used as a potential drug target to combat 2019CoV. 6LU7 has been structured in PDB and has been publicly available since early February, 2020. To date, this Mpro (6LU7) has been studied by different groups to find potential inhibitors that can stop this enzyme activity and, thus, the replication of CoVs. $8,27,28$

Nelfinavir, lopinavir, indinavir, and ritonaviprotease inhibitory drugs, of which ritonavir and lopinavir is proposed for treating SARS and MERS. ${ }^{29}$ In an in vitro study by Yamamoto et al. ${ }^{29}$, nelfinavir was reported to strongly inhibit the replication of SARS-CoV in Vero E6 cells. ${ }^{30}$ However, in an in silico study by Xu et al. ${ }^{5}$, nelfinavir was identified as the most potent inhibitor against COVID-19 with a binding free energy score. In our study, nelfinavir, lopinavir, indinavir, and ritonavir were used as standard drugs for comparison.

In this study, 35 secondary metabolites from medical plants were selected and docked into the active site of 6LU7. Docking studies were performed by AutoDockTools (ADT ver. 1.5.6). Table 1 shows the binding free energy scores of all selected molecules. The native ligand for $6 \mathrm{LU} 7$ is $n$-[(5-methylisoxazol3-yl) carbonyl]alanyl-I-valyl-n 1 - (1r,2z)-4-(benzyloxy)-4-oxo1-[[(3r)-2-oxopyrrolidin-3-yl] methyl]but-2-enyl)-l-leucinamide. According to the results presented in Table 1, the binding free energy scores of the compounds were between -11.30 $\mathrm{kcal} / \mathrm{mol}$ and $-4.13 \mathrm{kcal} / \mathrm{mol}$. We investigated pycnamine, tetrahydrocannabinol, oleuropein, quercetin, primulic acid, kaempferol, cannabidiol, lobeline, colchicine, piperidine, medicagenic acid, and narcotine as potential inhibitors of the COVID-19 Mpro because to the binding free energy scores of $-11.30,-9.10,-9.06,-8.94,-8.94,-8.70,-8.52,-8.30,-8.28,-7.74$, -7.71 , and $-7.60 \mathrm{kcal} / \mathrm{mol}$, respectively.

Analysis of docking results and interactions with six of these compounds are presented in Tables 2 and 3. Table 2 shows the analysis of molecular docking results (binding energy/Gibbs Energy, ligand efficiency, inhibition constant, intermolecular energy, and Van der Waals-H Bond desolvation energy) for the compounds with binding energies less than $-7.60 \mathrm{kcal} / \mathrm{mol}$, which is similar to the binding free energy of ritonavir.

Table 3 shows 2D and 3D visualizations of interactions between $6 \mathrm{LU} 7$ and the compounds presented in Table 2. According to Table 3, which shows interactions between compounds and 6LU7, nelfinavir forms $\mathrm{H}$-bonds with the amino acids Gly143, His163, Thr190, Gln189 of 6LU7. Lopinavir forms H-bonds with the amino acids His41, Cys145, Gln189, and Glu166. Indinavir realizes $\mathrm{H}$-bonds with the amino acid, i.e. Asn142, while ritonavir, the latest standard drug, forms $\mathrm{H}$-bonds with the amino acids His164 and Glu166. When the interactions of the seconder metabolites in Table 3 are evaluated, the following results are seen: pycnamine forms $\mathrm{H}$-bond with the amino acid, i.e. Glu166. Tetracannabinol forms $\mathrm{H}$-bonds with the amino acids Glu166, Cys145. Oleuropein realizes $\mathrm{H}$-bonds with the 6LU7 amino acids, e.g. His41, Thr26, Gly143, Glu166, and Thr190. Quercetin realizes H-bonds with 6LU7 amino acids, e.g. Glu166, Thr190, and His164. 
Table 1. Binding free energy scores of the compounds

\begin{tabular}{|c|c|c|c|}
\hline Compounds & Binding free energy $(\mathrm{kcal} / \mathrm{mol})$ & Compounds & Binding free energy $(\mathrm{kcal} / \mathrm{mol})$ \\
\hline Pycnamine & -11.30 & Harpagoside & -6.82 \\
\hline Tetrahydrocannabinol & -9.10 & Atropine & -6.70 \\
\hline Quercetin & -8.94 & Couscohygrin & -6.41 \\
\hline Primulic acid & -8.94 & Gingerol & -6.27 \\
\hline Cannabidiol & -8.52 & Tussulagin & -5.91 \\
\hline Lobeline & -8.30 & Castanospermine & -5.90 \\
\hline Colchicine & -8.28 & Pelletierin & -5.30 \\
\hline Piperidine & -7.74 & Citral-A & -4.98 \\
\hline Butylscopolamine & -7.42 & Hygrin & -4.55 \\
\hline Hyoscyamine & -7.39 & Ricinin & -4.51 \\
\hline Reticuline & -7.29 & Ivermektin & -4.13 \\
\hline Papaverine & -7.16 & Native ligand & -7.96 \\
\hline Codeine & -7.07 & Nelfinavir* & -10.70 \\
\hline Artemisinin & -7.03 & Lopinavir* & -8.95 \\
\hline Scopolamine & -6.97 & Indinavir* & -8.73 \\
\hline Morphine & -6.88 & Ritonavir* & -7.81 \\
\hline
\end{tabular}

*Nelfinavir, lopinavir, indinavir, and ritonavir are HIV protease inhibitor drugs

Table 2. Molecular docking results analysis of compounds with low binding energy scores and the drugs used in clinic

\begin{tabular}{|c|c|c|c|c|c|}
\hline Compounds & $\begin{array}{l}\text { Binding energy } \\
(\mathrm{kcal} / \mathrm{mol})\end{array}$ & Ligand efficiency & Inhibition constant & Intermolecular energy & $\begin{array}{l}\text { Van der Waals-H Bond } \\
\text { desolvation energy }\end{array}$ \\
\hline Pycnamine & -11.30 & -0.25 & $5.21 \mathrm{nM}$ & -12.20 & -11.85 \\
\hline Oleuropein & -9.06 & -0.25 & $229.87 \mathrm{nM}$ & -13.23 & -12.96 \\
\hline Quercetin & -8.94 & -0.41 & $277.84 \mathrm{nM}$ & -9.24 & -9.13 \\
\hline Kaempferol & -8.70 & -0.41 & $422.9 \mathrm{nM}$ & -8.99 & -8.88 \\
\hline Cannabidiol & -8.52 & -0.37 & $570.21 \mathrm{nM}$ & -10.01 & -9.97 \\
\hline Lobeline & -8.30 & -0.33 & $821.52 \mathrm{nM}$ & -10.09 & -9.98 \\
\hline Colchicine & -8.28 & -0.29 & $-856.99 \mathrm{nM}$ & -9.77 & -9.66 \\
\hline Narcotine & -7.60 & -0.25 & $2.69 \mu \mathrm{M}$ & -8.79 & -8.42 \\
\hline Nelfinavir & -10.70 & -0.27 & $14.45 \mathrm{nM}$ & -12.78 & -12.72 \\
\hline Lopinavir & -8.95 & -0.19 & $275.32 \mathrm{nM}$ & -13.72 & -13.55 \\
\hline Indinavir & -8.73 & -0.19 & $400.34 \mathrm{nM}$ & -12.90 & -12.33 \\
\hline Ritonavir & -7.81 & -0.16 & $1.9 \mu \mathrm{M}$ & -13.47 & -13.39 \\
\hline
\end{tabular}


Table 3. Two-dimensional and three-dimesnsional interaction diagrams for several compounds

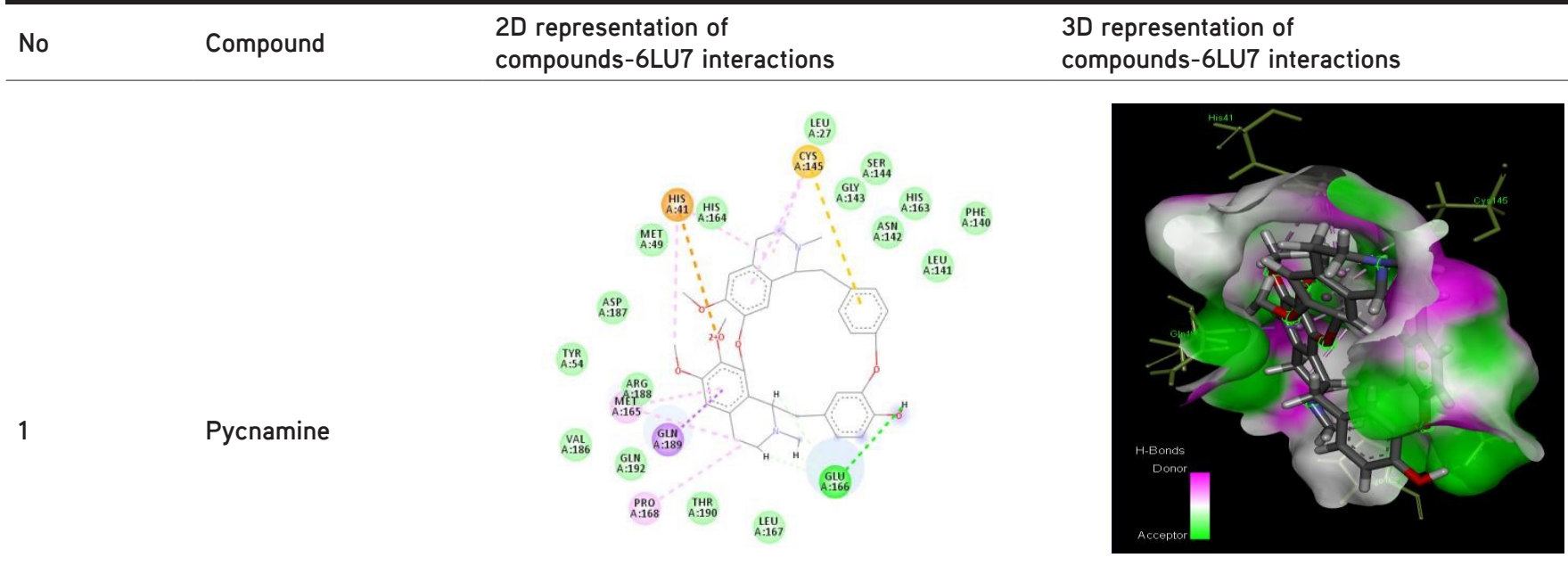

2

Tetrahydrocannabinol
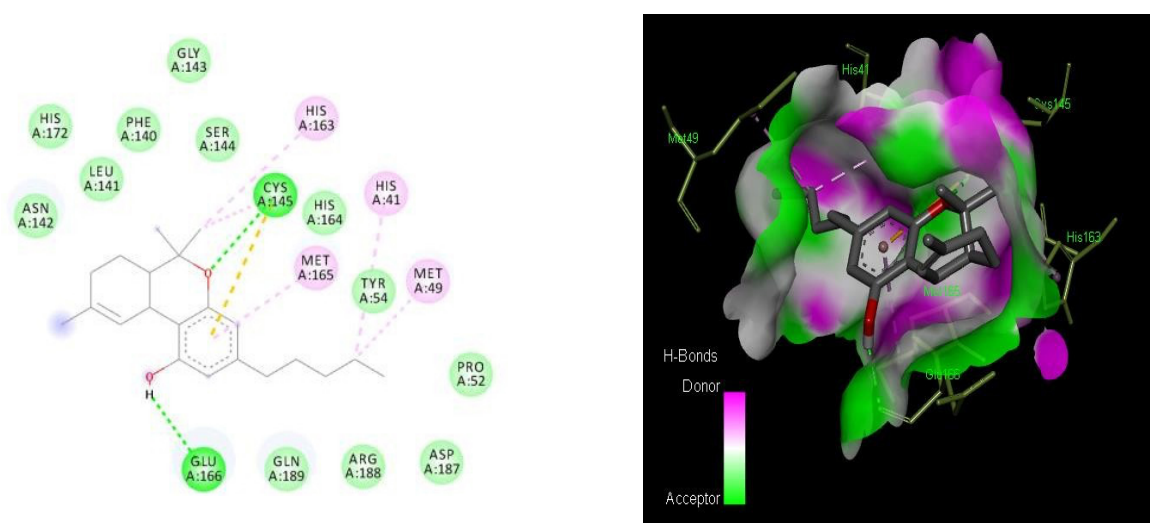

3

Oleuropein
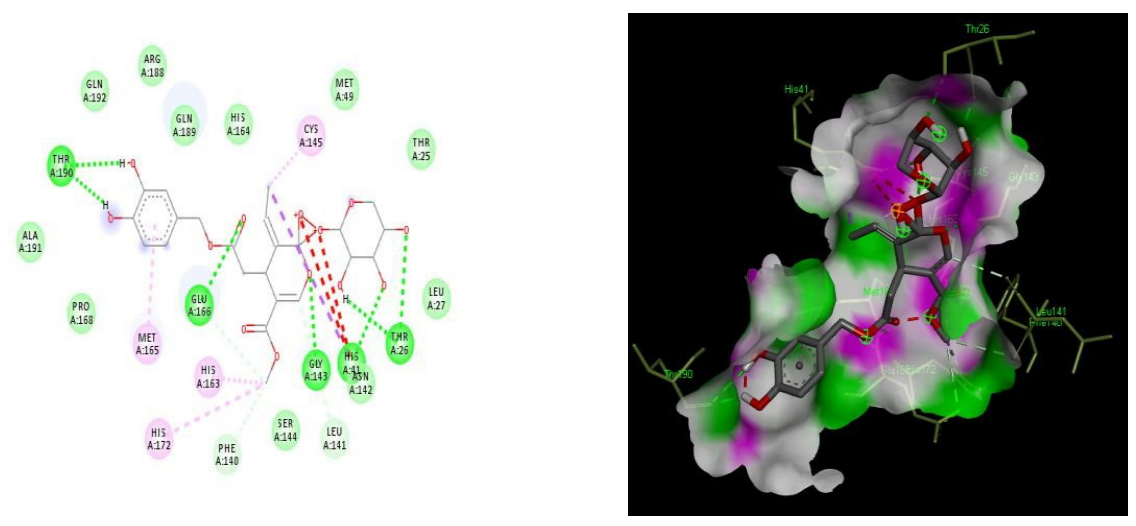

4

Quercetin
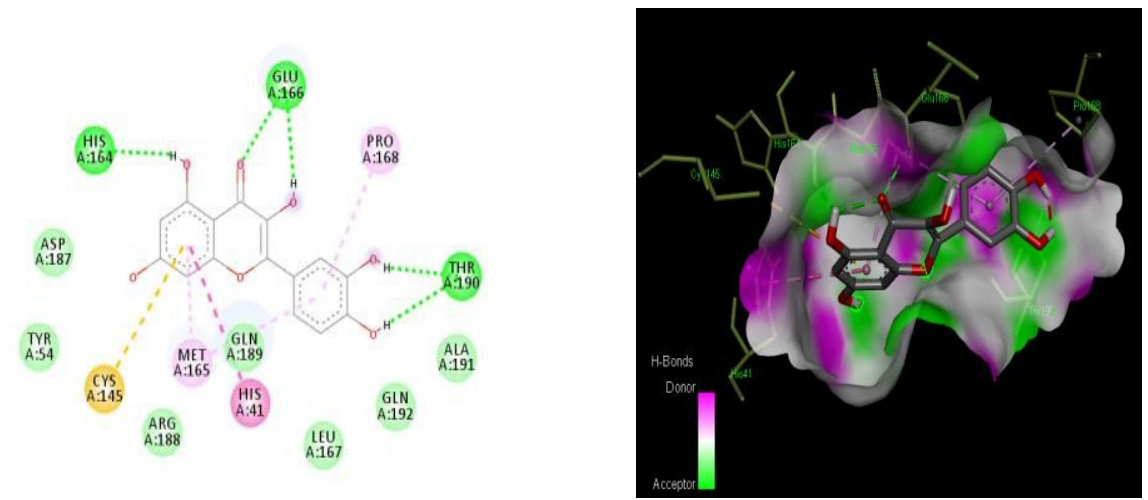
5

Primulic acid
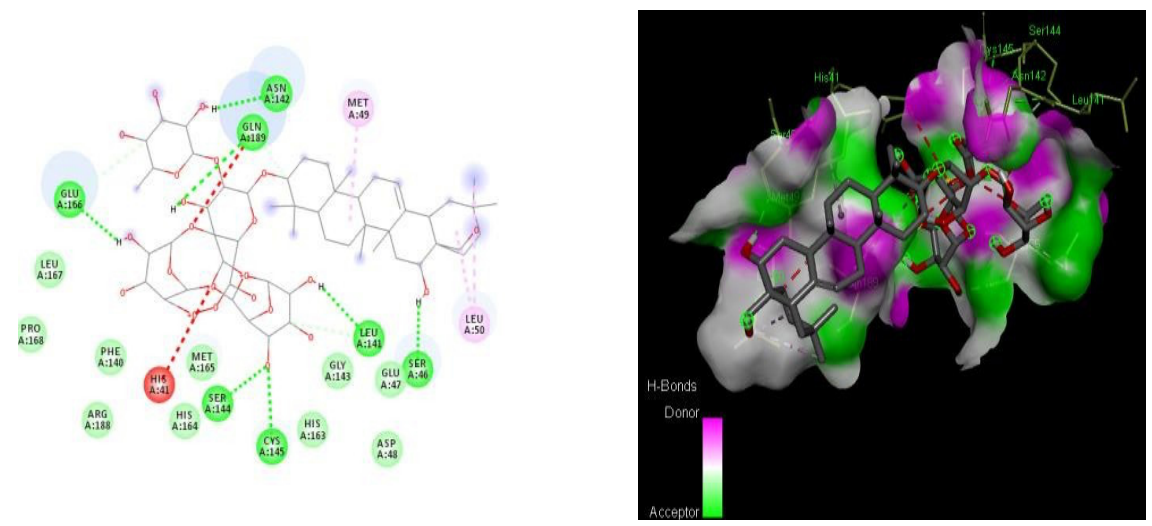

6

Kaempferol
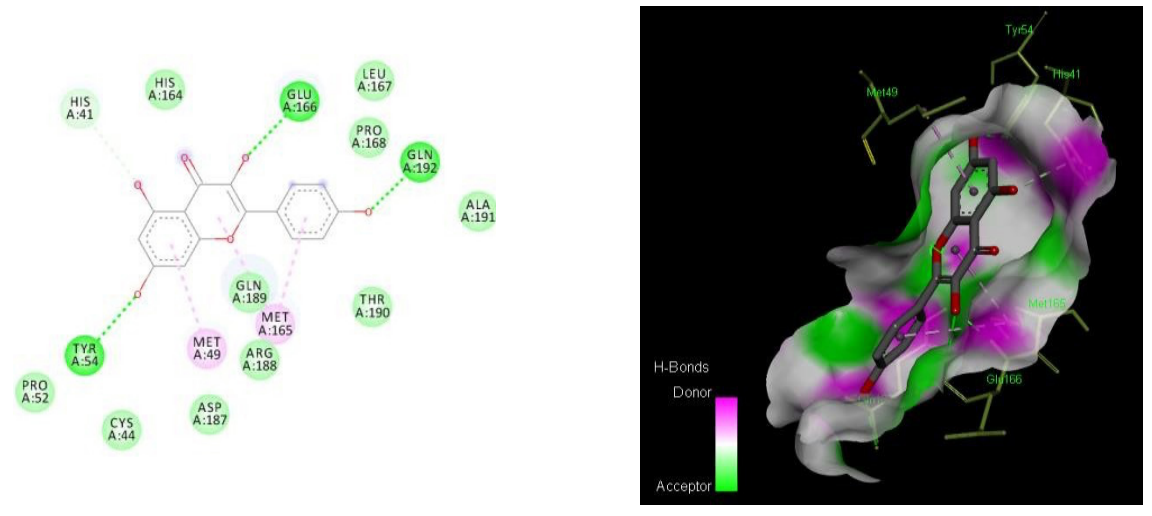

7

Cannabidiol
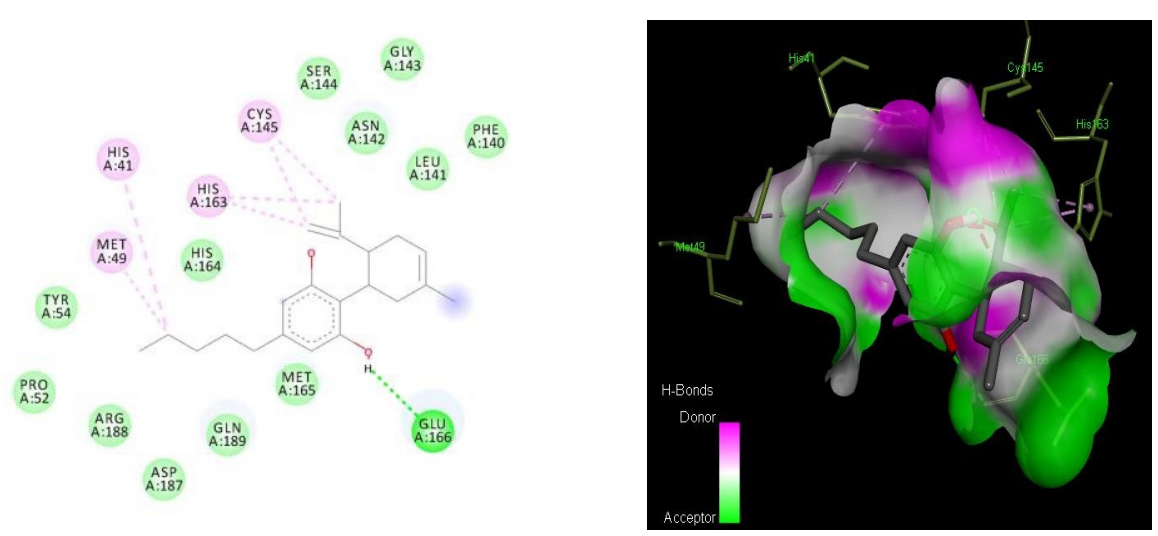

8

Lobeline
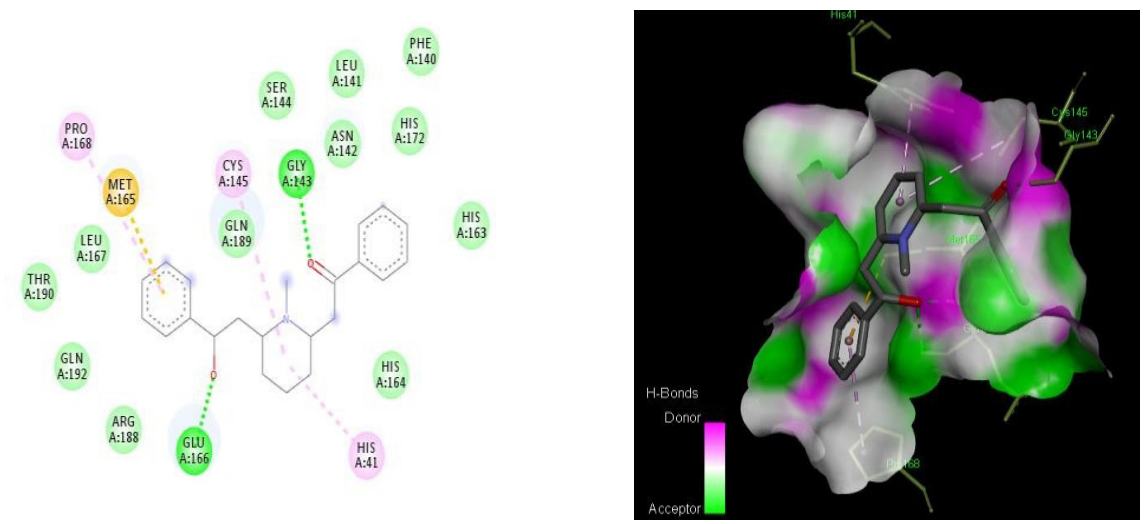
9

\section{Colchicine}
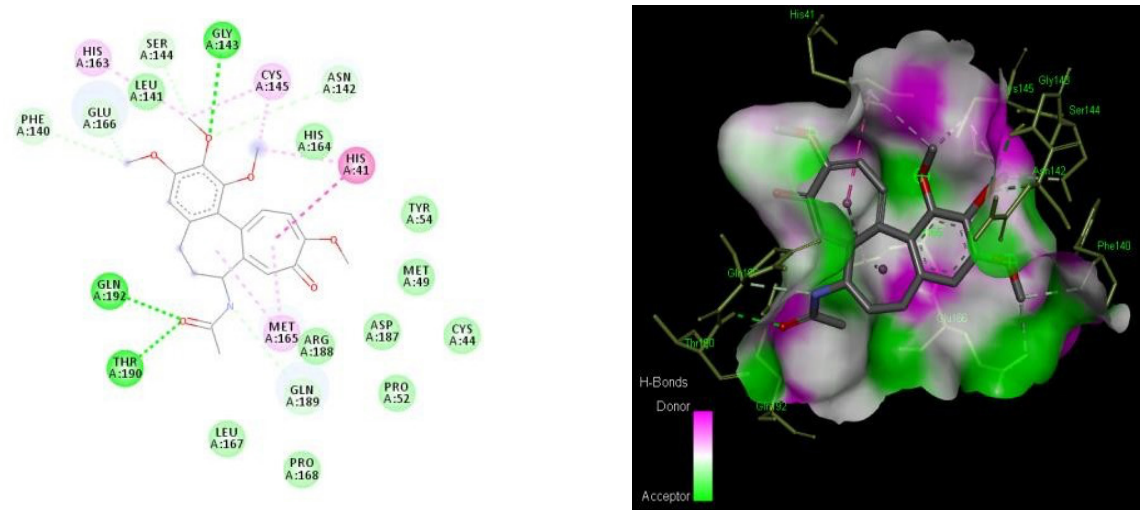

10

Piperidine
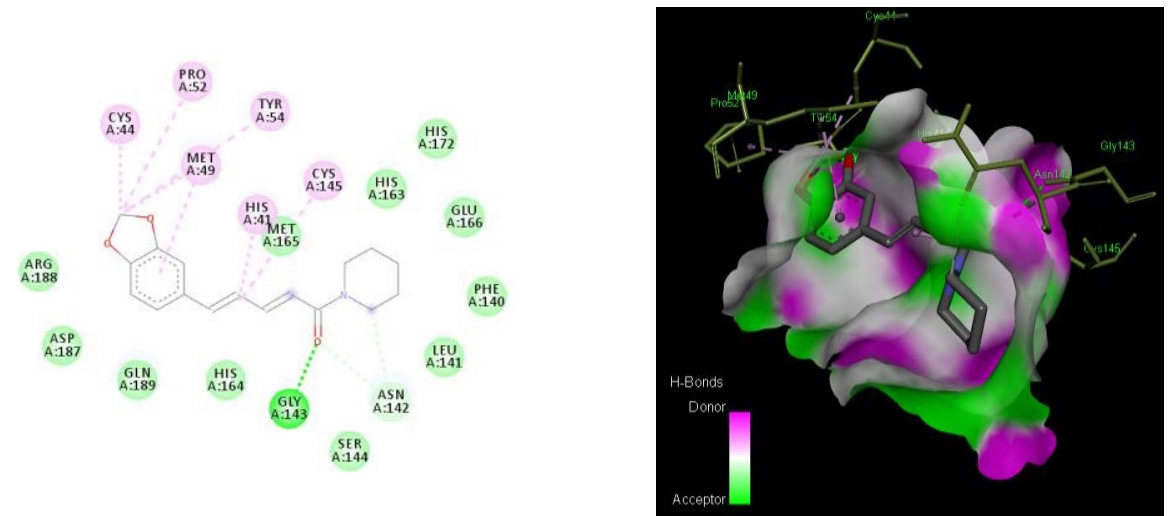

11

Medicagenic acid
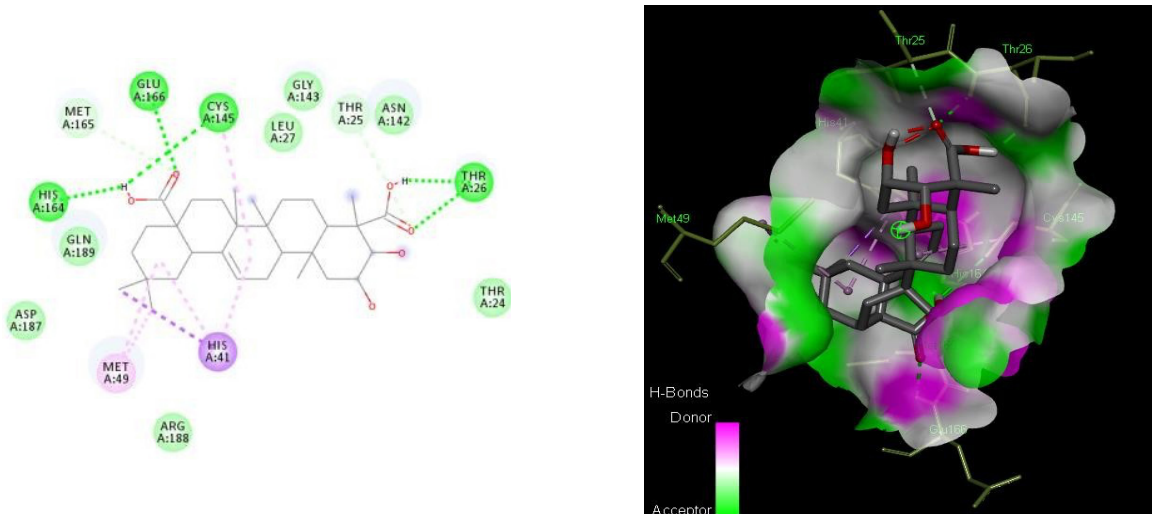

Narcotine
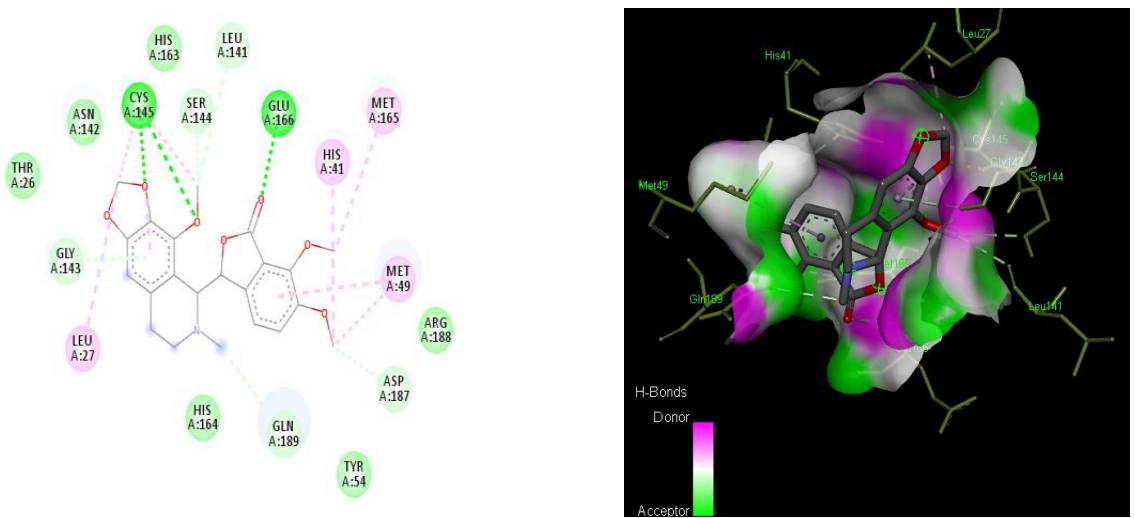
Nelfinavir

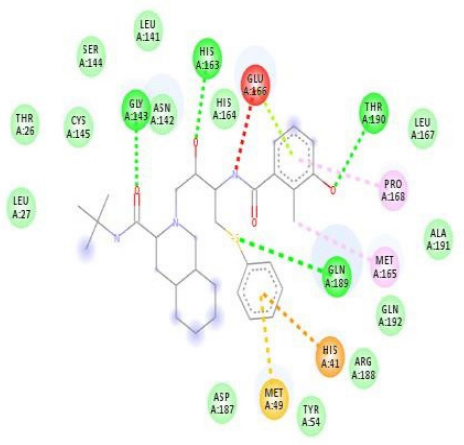

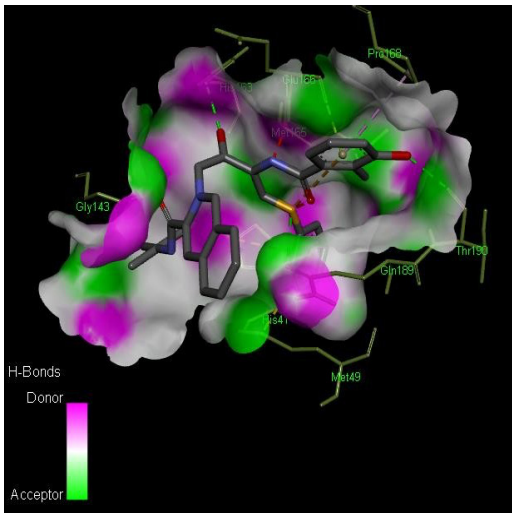

14

Lopinavir
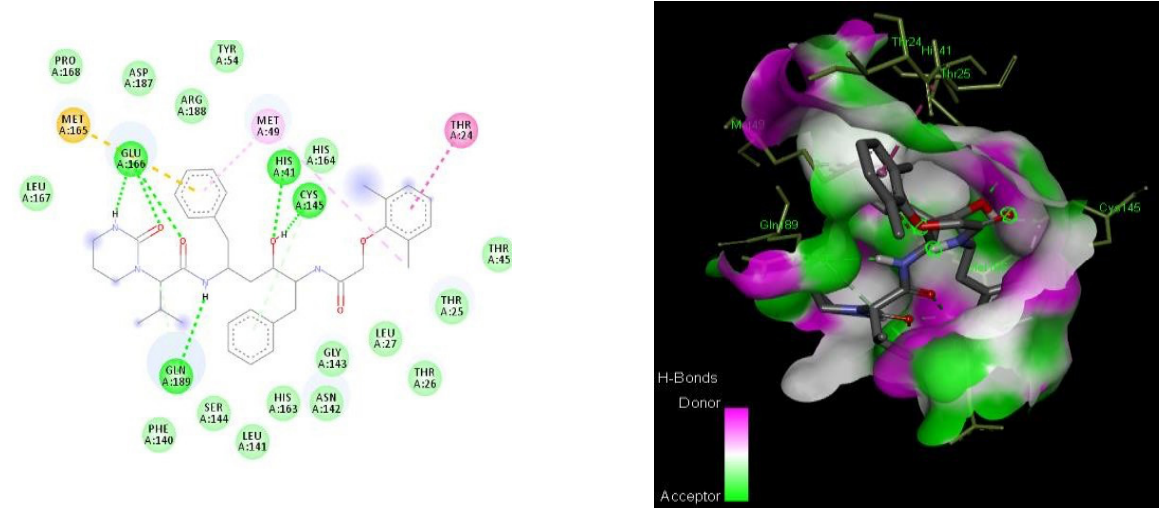

15

Indinavir
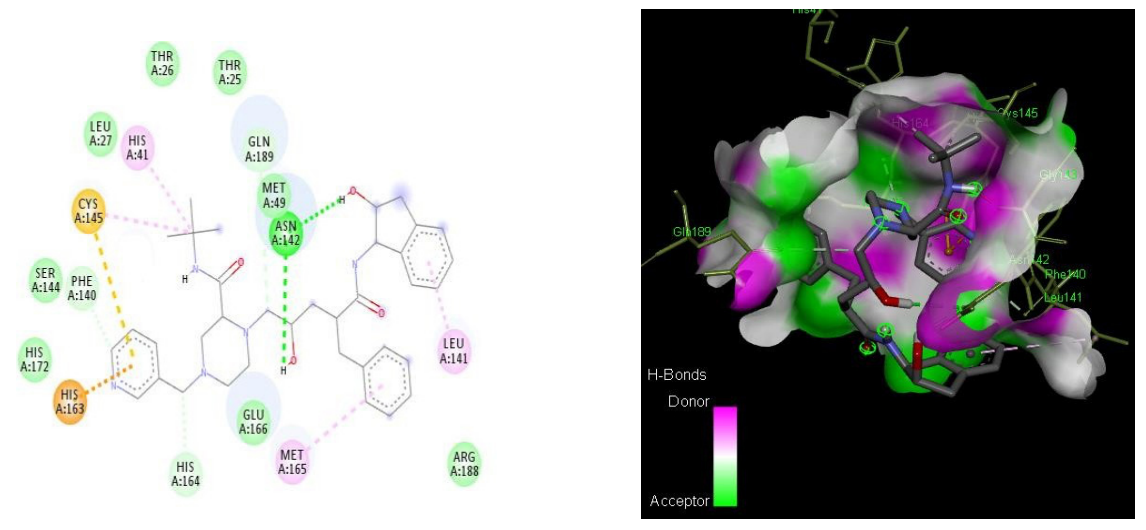

Ritonavir
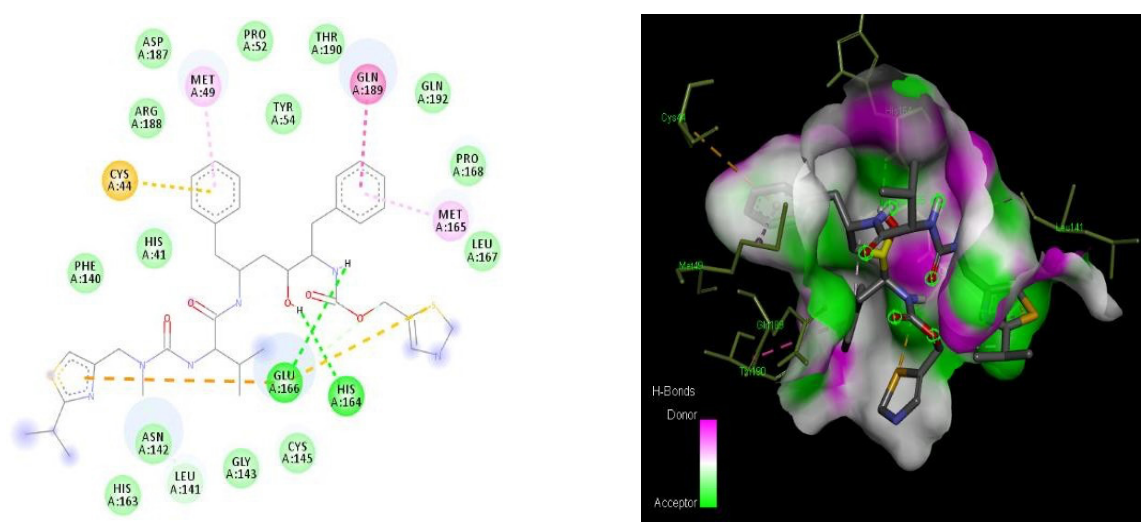
Primulic acid forms H-bonds with the amino acids, e.g. Ser46, Ser144, Glu166, Gln189, Asn142, Cys145, and Leu141. Kaempferol forms $\mathrm{H}$-bonds with the 6LU7 amino acids, e.g. Tyr54, Glu166, and GIn192. Dicannabidiol realizes H-bond with the 6LU7 amino acid, i.e. Glu166. Lobelin realizes H-bonds with the amino acids, e.g. Gly143 and Glu166. Colchicine realizes H-bonds with the amino acids, e.g. Gly143, Thr190, Gln189, and Gln192. Piperidine forms $\mathrm{H}$-bonds with the amino acids, e.g. Gly143 and Asn142. Medicagenic acid forms $\mathrm{H}$ - bonds with the amino acids, e.g. Thr26, Cys145, Glu166, and His164. Narcotine realizes H- bonds with the 6LU7 amino acids, e.g. Cys145 and Glu169. The results presented in Table 3 suggest that the $\mathrm{M}^{\text {pro }}$ Glu166 plays a crucial role in drug interactions. Besides, the other amino acids, e.g. Asn142, Gln189, Cys145, and Thr26 are also predicted to play roles in drug interactions, as reported in previous studies. 8,27

According to the results in Tables 1 and 2, the most impressive compound of our study is pycnamine with a score of $-11.30 \mathrm{kcal} /$ mol, which is higher than that of nelfinavir. When the results in Table 2 are evaluated, it is seen that pycnamine has a predicted inhibition constant value (5.21 nM) approximately 3 times lower than that of nelfinavir (14.45 nM). According to pycnamine-6LU7 complex presented in Table 3, hydroxy moiety of pycnamine forms a hydrogen bond with the side chain of Glu166. Additionally, pycnamine forms $\pi$-cation, $\pi$-sulfur, $\pi$-sigma, and several hydrophobic interactions with the active site of 6LU7, as shown in Table 3.

\section{DISCUSSION}

Pycnamine is an alkaloid found in some species of Menispermaceae (Triclisia patens Oliv., $T$. dictyophylla Diels, Pycnarrhena manillensis Vidal, P. ozantha Diels) and Ranunculaceae families (Thalictrum cultratum Wall., Isopyrum thalictroides L.). ${ }^{31-36}$ Pycnamine was reported to be a potential antimalarial, antiplasmodial, antiamoebic, and antimicrobial in previous studies. ${ }^{36-40}$ It was evaluated against COVID-19 for the first time in this study.

Tetrahydrocannabinol, which has the second lowest binding free energy score $(-9.10 \mathrm{kcal} / \mathrm{mol})$ in this study, purified from Cannabis sativa L. was reported to inhibit macrophage extrinsic antiherpesvirus activity. ${ }^{41}$

Oleuropein, a secoiridoid monoterpene and the main component of Olea europaea L., is a potential inhibitor of the COVID-19 Mpro due to it is binding free energy score of $-9.06 \mathrm{kcal} / \mathrm{mol}$. It has antiviral activity against mononucleosis herpes, hepatitis, rota, bovine, parvo, HIV, leukemia, respiratory syncytial, parainfluenza-3, and salmonid rhabdoviruses. ${ }^{42-46}$ In hepatitis $B$ virus infected ducks, oleuropein reduced the virus entering the bloodstream. ${ }^{47}$

Quercetin, a flavonoid, is found abundantly in fruits and vegetables including onions, broccoli, buckwheat, peppers, Brassica species, apples, grapes, berries, tea, and wine as well as many nuts, seeds, barks, flowers, leaves, and spices. ${ }^{48}$

Quercetin also demonstrated a dose-dependent antiviral activity against poliovirus type 1, Herpes simplex virus (HSV-
1, HSV-2), and respiratory syncytial virus, influenza virus strain, parainfluenza virus type-3, sindbis virus, rhinovirus, echovirus (types-7, -11, -12, and -19), coxsackievirus (A21 and B1), poliovirus (type-1 Sabin) and grouper iridovirus in cell cultures. ${ }^{49-53}$ Early in vivo studies showed that oral treatment with quercetin-protected mice from lethal Mengo virus. ${ }^{54}$ In mice infected with rhinovirus, quercetin treatment decreased viral replication and attenuates virus- induced airway cholinergic hyperresponsiveness. ${ }^{55}$

Kaempferol is another flavonoid derivative found in most edible plants such as tea, fruits, and vegetables consisting of Allium cepa L., Camellia sinensis (L.) Kuntze, Citrus paradisi Macfad., Fragaria vesca L., Lactuca sativa L., and in medicinal plants such as Tilia tomentosa Moench., Aloe vera L., Crocus sativus L., Vitis vinifera L., Ginkgo biloba L., Hypericum perforatum L., Phyllanthus acidus L., Ribes nigrum L., Rosmarinus officinalis L., Hippophae rhamnoides L., and Sambucus nigra L. ${ }^{56}$ Antiviral activity of kaempferol on the influenza viruses (H1N1 and H9N2), HIV-1, flavivirus, two RNA viruses (murine norovirus and feline calicivirus), and human cytomegalovirus were mentioned. 14,48,51,57,58

Primulic acid is a saponin found in some species of Primulaceae [Primula officinalis L., P. elatior (L.) Hill, P. veris L.] and Poaceae (Panicum repens L.), ${ }^{59-63}$ and was reported to have antiviral activity by Helal and Melzig. ${ }^{58}$

Finally, cannabidiol, the potential inhibitor of COVID-19 $\mathrm{M}^{\text {pro, }}$, purified from the C. sativa L., ${ }^{64,65}$ and was reported to show high efficacy against viral hepatitis in previous studies. ${ }^{64}$

\section{CONCLUSION}

At currently, there is no antiviral drug for specific treatment of COVID-19, which is still a threat to global health. Mpro was used as a potential drug target to combat 2019-CoV. In this study, we evaluated several secondary metabolites obtained from medicinal plants against COVID-19 Mpro by molecular docking studies to identify a potential inhibitory compound that may be used to inhibit COVID-19 infection pathway. According to the results, pycnamine, tetrahydrocannabinol, oleuropein, quercetin, primulic acid, kaempferol, cannabidiol, lobeline, colchicine, piperidine, medicagenic acid, and narcotine are found to be potential inhibitors of COVID-19 Mro. Among these compounds, pycnamine, which was evaluated against COVID-19 for the first time, showed high affinity to COVID-19 M $\mathrm{M}^{\text {ro }}$ compared with other seconder metabolites and reference drugs. According to the results in this study, pycnamine has a binding free energy score of $-11.30 \mathrm{kcal} / \mathrm{mol}$, which is higher than nelfinavir used in clinics as the most potent inhibitor drug against COVID-19 $\mathrm{M}^{\text {pro. }}$. As a conclusion, this study has clearly shown that pycnamine may strongly inhibit COVID-19 Mpro. Our results obtained from the docking studies suggest that pycnamine should be examined in vitro to combat 2019-CoV. Moreover, pycnamine might be a promising lead compound for anti-CoV drugs. 
Ethics

Ethics Committee Approval: Not applicable.

Informed Consent: Not applicable.

Peer-review: Externally peer-reviewed.

\section{Authorship Contributions}

Concept: S.G., S.B., Design: S.B., Data Collection or Processing: S.B., S.G., Z.G., Analysis or Interpretation: S.B., S.G., Literature Search: S.B., S.G., Z.G., Writing: S.B., S.G., Z.G.

Conflict of Interest: No conflict of interest was declared by the authors.

Financial Disclosure: The authors declared that this study received no financial support.

\section{REFERENCES}

1. Khaerunnisa S, Kurniawan $H$, Awaluddin R, Suhartati S, Soetjipto S. Potential inhibitor of COVID-19 main protease $\left(M^{\text {pro }}\right)$ from several medicinal plant compounds by molecular docking study. Preprint. doi: 10.20944/preprints202003.0226.v1.

2. Bolelli K, Ertan-Bolelli T, Unsalan O, Altunayar-Unsalan C. Fenoterol and dobutamine as SARS-CoV-2 main protease inhibitors: a virtual screening study. J Mol Struct. 2021;1228:129449.

3. WHO. COVID-19 Weekly Epidemiological Update Report. World Health Organization; 11 May 2021. p. 1-2.

4. Wang Z, Chen X, Lu Y, Chen F, Zhang W. Clinical characteristics and therapeutic procedure for four cases with 2019 novel coronavirus pneumonia receiving combined Chinese and Western medicine treatment. Biosci Trends. 2020;14:64-68. Erratum in: Biosci Trends. 2020;14:E1.

5. Xu Z, Peng C, Shi Y, Zhu Z, Mu K, Wang X, Zhu W. Nelfinavir was predicted to be a potential inhibitor of 2019-nCov main protease by an integrative approach combining homology modelling, molecular docking and binding free energy calculation. BioRxiv. 2020. doi: https://doi. org/10.1101/2020.01.27.921627.

6. Chang YC, Tung YA, Lee KH, Chen TF, Hsiao YC, Chang HC, Hsieh TT, Su CH, Wang SS, Yu JY, Shih SS, Lin YH, Lin YH, Tu YCE, Chen CY. Potential therapeutic agents for COVID-19 based on the analysis of protease and RNA polymerase docking. Preprint. 2020. doi: 10.20944/ preprints202002.0242.v2

7. Durdagi S, Orhan MD, Aksoydan B, Calis S, Dogan B, Sahin K, Shahraki A, lyison NB, Avsar T. Screening of clinically approved and investigation drugs as potential inhibitors of SARS-CoV-2: a combined in silico and in vitro study. Mol Inform. 2022;41:e2100062.

8. Orhan IE, Senol Deniz FS. Natural products as potential leads against coronaviruses: could they be encouraging structural models against SARS-CoV-2? Nat Prod Bioprospect. 2020;10:171-186.

9. Kumar S, Maurya VK, Kabir R, Nayak D, Khurana A, Manchanda RK, Gadugu S, Shanker K, Saxena SK. Antiviral activity of belladonna during Japanese encephalitis virus infection via inhibition of microglia activation and inflammation leading to neuronal cell survival. ACS Chem Neurosci. 2020;11:3683-3696.

10. Yang CW, Lee $Y Z$, Kang IJ, Barnard DL, Jan JT, Lin D, Huang CW, Yeh TK, Chao YS, Lee SJ. Identification of phenanthroindolizines and phenanthroquinolizidines as novel potent anti-coronaviral agents for porcine enteropathogenic coronavirus transmissible gastroenteritis virus and human severe acute respiratory syndrome coronavirus. Antiviral Res. 2010;88:160-168.

11. Kang KB, Ming G, Kim GJ, Ha TK, Choi H, Oh WK, Sung SH. Jubanines F-J, cyclopeptide alkaloids from the roots of Ziziphus jujuba. Phytochemistry. 2015;119:90-95.

12. Wu W, Li R, Li X, He J, Jiang S, Liu S, Yang J. Quercetin as an antiviral agent inhibits influenza A virus (IAV) entry. Viruses. 2015;8:6.

13. Behbahani M, Sayedipour S, Pourazar A, Shanehsazzadeh M. In vitro anti-HIV-1 activities of kaempferol and kaempferol-7-0-glucoside isolated from Securigera securidaca. Res Pharm Sci. 2014;9:463-469.

14. Fredrickson WR. Method and composition for antiviral therapy. Google Patents; 2000.

15. Lai WL, Chuang HS, Lee MH, Wei CL, Lin CF, Tsai YC. Inhibition of Herpes simplex virus type 1 by thymol-related monoterpenoids. Planta Med. 2012;78:1636-1638.

16. Ma SC, He ZD, Deng XL, But PP, Ooi VE, Xu HX, Lee SH, Lee SF. In vitro evaluation of secoiridoid glucosides from the fruits of Ligustrum lucidum as antiviral agents. Chem Pharm Bull (Tokyo). 2001;49:1471-1473.

17. Astani A, Reichling J, Schnitzler P. Comparative study on the antiviral activity of selected monoterpenes derived from essential oils. Phytother Res. 2010;24:673-679.

18. Bermejo P, Abad MJ, Díaz AM, Fernández L, De Santos J, Sanchez S, Villaescusa L, Carrasco L, Irurzun A. Antiviral activity of seven iridoids, three saikosaponins and one phenylpropanoid glycoside extracted from Bupleurum rigidum and Scrophularia scorodonia. Planta Med. 2002;68:106-110.

19. Efferth T, Romero MR, Wolf DG, Stamminger T, Marin JJ, Marschall M. The antiviral activities of artemisinin and artesunate. Clin Infect Dis. 2008;47:804-811.

20. Romero MR, Serrano MA, Vallejo M, Efferth T, Alvarez M, Marin JJ. Antiviral effect of artemisinin from Artemisia annua against a model member of the Flaviviridae family, the bovine viral diarrhoea virus (BVDV). Planta Med. 2006;72:1169-1174.

21. De Tommasi N, Conti C, Stein ML, Pizza C. Structure and in vitro antiviral activity of triterpenoid saponins from Calendula arvensis. Planta Med. 1991;57:250-253.

22. Pecetti L, Biazzi E, Tava A. Variation in saponin content during the growing season of spotted medic [Medicago arabica (L.) Huds.]. J Sci Food Agric. 2010;90:2405-2410.

23. Oso BJ, Adeoye AO, Olaoye IF. Pharmacoinformatics and hypothetical studies on allicin, curcumin, and gingerol as potential candidates against COVID-19-associated proteases. J Biomol Struct Dyn. 2022;40:389-400.

24. Patwardhan M, Morgan MT, Dia V, D'Souza DH. Heat sensitization of hepatitis A virus and Tulane virus using grape seed extract, gingerol and curcumin. Food Microbiol. 2020;90:103461.

25. Bilginer S, Gul HI, Anil B, Demir Y, Gulcin I. Synthesis and in silico studies of triazene-substituted sulfamerazine derivatives as acetylcholinesterase and carbonic anhydrases inhibitors. Arch Pharm (Weinheim). 2021;354:e2000243.

26. Samant L, Javle V. Comparative docking analysis of rational drugs against COVID-19 main protease. Biological Med. Chem 2020.

27. Hatada R, Okuwaki K, Mochizuki Y, Handa Y, Fukuzawa K, Komeiji Y, Okiyama $\mathrm{Y}$, Tanaka S. Fragment molecular orbital based interaction 
analyses on COVID-19 main protease - inhibitor N3 complex (PDB ID: 6LU7). J Chem Inf Model. 2020;60:3593-3602.

28. Li JY, You Z, Wang Q, Zhou ZJ, Qiu Y, Luo R, Ge XY. The epidemic of 2019-novel-coronavirus (2019-nCoV) pneumonia and insights for emerging infectious diseases in the future. Microbes Infect. 2020;22:8085.

29. Yamamoto N, Yang R, Yoshinaka Y, Amari S, Nakano T, Cinatl J, Rabenau H, Doerr HW, Hunsmann G, Otaka A, Tamamura H, Fujii N, Yamamoto N. HIV protease inhibitor nelfinavir inhibits replication of SARS-associated coronavirus. Biochem Biophys Res Commun. 2004;318:719-725.

30. Spiff Al, Zabel V, Watson WH, Zemaitis MA, Ateya AM, Slatkin DJ, Knapp JE, Schiff PL Jr. Constituents of West African medicinal plants. XXX. Tridictyophylline, a new morphinan alkaloid from Triclisia dictyophylla. J Nat Prod. 1981;44:160-165.

31. Valentin A, Benoit-Vical F, Moulis C, Stanislas E, Mallié M, Fouraste I, Bastide JM. In vitro antimalarial activity of penduline, a bisbenzylisoquinoline from Isopyrum thalictroides. Antimicrob Agents Chemother. 1997; 41:2305-2307.

32. Hernandez E, Santos A. Alkaloid of Pycnarrhena manillensis vidal. (family Menispermaceae). Constitution of Pycnamine. (Thesis) University of the Philippines. 28 pp., 1935. Jour. Philippine Pharm. 1946.

33. Gupta NC, Bhakuni DS, Dhar MM. Pendulin, a new biscoclaurine alkaloid from Cocculus pendulus Diels. Experientia. 1970;26:12-13.

34. Lin M. Part I. Isolation and identification of quaternary alkaloids from the roots of Thalictrum cultratum Wall. (Ranunculaceae). Part II. Isolation and identification of alkaloids from the roots and stems of Pycnarrhena manillensis Vidal (Menispermaceae) ('st ed). St. Petersburg; 1989:79-85.

35. Ragasa CY, Tepora MM, Rideout J. Antimicrobial activities of sterol from Pycnarrhena manillensis. ACGC Chemical Res Comm. 2009;23:31-34.

36. Simanjuntak P. Tumbuhan sebagai sumber zat aktif antimalaria. Repositori Riset Kesehatan Nasional. 2019;46:125-132.

37. Marshall SJ, Russell PF, Wright CW, Anderson MM, Phillipson JD, Kirby GC, Warhurst DC, Schiff PL Jr. In vitro antiplasmodial, antiamoebic, and cytotoxic activities of a series of bisbenzylisoquinoline alkaloids. Antimicrob Agents Chemother. 1994;38:96-103.

38. Sharma P, Sharma JD. A review of plant species assessed in vitro for antiamoebic activity or both antiamoebic and antiplasmodial properties. Phytother Res. 2001;15:1-17.

39. Kodi P. Antiplasmodial and toxicity activities and characterization of chemical compounds extracted from selected medicinal plants in Uganda ( ${ }^{\text {st }}$ ed). Njero; Egerton University, 2018:87-95.

40. Cabral GA, Vasquez R. Delta 9-tetrahydrocannabinol suppresses macrophage extrinsic antiherpesvirus activity. Proc Soc Exp Biol Med. 1992;199:255-263.

41. Nediani C, Ruzzolini J, Romani A, Calorini L. Oleuropein, a bioactive compound from Olea europaea $\mathrm{L}$., as a potential preventive and therapeutic agent in non-communicable diseases. Antioxidants (Basel). 2019;8:578.

42. Barbaro B, Toietta G, Maggio R, Arciello M, Tarocchi M, Galli A, Balsano C. Effects of the olive-derived polyphenol oleuropein on human health. Int J Mol Sci. 2014;15:18508-18524.

43. Karaboğa Arslan AK, Öztürk E, Yerer MB, Koşar M. Oleuropein in olive leaf and its pharmacologial effects. J Health Sci. 2017;26:89-93.
44. Micol V, Caturla N, Pérez-Fons L, Más V, Pérez L, Estepa A. The olive leaf extract exhibits antiviral activity against viral haemorrhagic septicaemia rhabdovirus (VHSV). Antiviral Res. 2005;66:129-136.

45. Omar SH. Oleuropein in olive and its pharmacological effects. Sci Pharm. 2010;78:133-154.

46. Zhao G, Yin Z, Dong J. Antiviral efficacy against hepatitis B virus replication of oleuropein isolated from Jasminum officinale $\mathrm{L}$. var. grandiflorum. J Ethnopharmacol. 2009;125:265-268.

47. Bureau S, Ruiz D, Reich M, Gouble B, Bertrand D, Audergon JM, Renard CMGC. Rapid and non-destructive analysis of apricot fruit quality using FT-near-infrared spectroscopy. Food Chem. 2009;113:1323-1328.

48. Liu M, Yu Q, Xiao H, Li M, Huang Y, Zhang Q, Li P. The inhibitory activities and antiviral mechanism of medicinal plant ingredient quercetin against grouper iridovirus infection. Front Microbiol. 2020;11:586331.

49. Lyu SY, Rhim JY, Park WB. Antiherpetic activities of flavonoids against Herpes simplex virus type 1 (HSV-1) and type 2 (HSV-2) in vitro. Arch Pharm Res. 2005;28:1293-1301.

50. Zakaryan H, Arabyan E, Oo A, Zandi K. Flavonoids: promising natural compounds against viral infections. Arch Virol. 2017;162:2539-2551.

51. Debiaggi M, Tateo F, Pagani L, Luini M, Romero E. Effects of propolis flavonoids on virus infectivity and replication. Microbiologica. 1990;13:207-213.

52. De Palma AM, Vliegen I, De Clercq E, Neyts J. Selective inhibitors of picornavirus replication. Med Res Rev. 2008;28:823-884.

53. Agrawal PK, Agrawal C, Blunden G. Quercetin: antiviral significance and possible COVID-19 integrative considerations. Nat Prod Commun. 2020;15:1-10.

54. Ganesan S, Faris AN, Comstock AT, Wang Q, Nanua S, Hershenson MB, Sajjan US. Quercetin inhibits rhinovirus replication in vitro and in vivo. Antiviral Res. 2012;94:258-271.

55. Hossen MJ, Uddin MB, Ahmed SSU, Yu Z-L, Cho JY. Kaempferol: review on natural sources and bioavailability. Kaempferol: Biosynthesis, Food Sources and Therapeutic Uses; Nova Science Publishers: New York, NY, USA. 2016:101-150.

56. Jeong HJ, Ryu YB, Park SJ, Kim JH, Kwon HJ, Kim JH, Park KH, Rho $M C$, Lee WS. Neuraminidase inhibitory activities of flavonols isolated from Rhodiola rosea roots and their in vitro anti-influenza viral activities. Bioorg Med Chem. 2009;17:6816-6823.

57. Zhang W, Qiao H, Lv Y, Wang J, Chen X, Hou Y, Tan R, Li E. Apigenin inhibits enterovirus-71 infection by disrupting viral RNA association with trans-acting factors. PLoS One. 2014;9:e110429.

58. Helal R, Melzig MF. In vitro effects of selected saponins on the production and release of lysozyme activity of human monocytic and epithelial cell lines. Sci Pharm. 2011;79:337-349.

59. Czarnecki R, Librowski T. The effect of primulic acid on experimental, chronic venous insufficiency. Eur J Pharm Sci. 1996:121.

60. Grecu L, Cucu V. Saponine aus Primula officinalis and Primula elatior. Planta Med. 1975;27:247-253.

61. Morozowska M. Vegetative development, flowering, fruiting and saponin content in cultivated cowslip [Primula veris L.] plants. Herba Pol. 2004:2. 
62. El-Tantawy WH, Temraz A, Hozaien HE, El-Gindi OD, Taha KF. Antihyperlipidemic activity of an extract from roots and rhizomes of Panicum repens $\mathrm{L}$. on high cholesterol diet-induced hyperlipidemia in rats. $Z$ Naturforsch C J Biosci. 2015;70:139-144.

63. Martinenghi LD, Jønsson R, Lund T, Jenssen $\mathrm{H}$. Isolation, purification, and antimicrobial characterization of cannabidiolic acid and cannabidiol from Cannabis sativa L. Biomolecules. 2020;10:900.
64. Adams R, Pease DC, Clark JH. Isolation of cannabinol, cannabidiol and quebrachitol from red oil of Minnesota wild hemp. J Am Chem Soc. 1940;62:2194-2196.

65. Lowe HI, Toyang NJ, McLaughlin W. Potential of cannabidiol for the treatment of viral hepatitis. Pharmacognosy Res. 2017;9:116-118. 